TURIZAM

Volume 21, Issue 1

19-33 (2017)

ORIGINAL

SCIENTIFIC PAPER

\title{
Measurement of the Financial Risk and Forecasting the Mispricing of Volatility in Indian Market
}

\author{
Nenavath Sreenu ${ }^{\mathrm{A}}$ \\ Received: Januar 2017 | Accepted: March 2017 \\ DOI: 10.18421/TRZ21.01-02
}

\begin{abstract}
The present research paper main objective is that the study of Measurement of the Financial Risk and Mispricing of Volatility in the present scenario in the Indian equity. Money and debt market while the traditional theory explored in the present situation that high returns of money are associated with high risks, The market appears to be underestimating the probability of market movements in either direction, and thereby underpricing volatility severely in the research paper shows in that under certain conditions, a portfolio with low volatility stocks can yield higher returns than a high-volatility portfolio. Market operation is unacceptable in any financial market even if this influence is performed by the state itself. Moreover market operation to reduce interest rates would reintroduce financial repression through the back door and would reverse the principal success of the financial sector reforms.

The main agenda of this research paper is the relatively new phenomenon of 'Risk-based anomaly. The present study mainly using a low-volatility portfolio strategy over a 6-year period (from 2010 to 2016) with rolling monthly iterations in the Indian money market, The present Research Paper main proposes a substitute design for the government securities market and also a new monitoring construction. Integrated markets, unbiased access to all modules of investors, intense competition and investor safety are the key elements of the anticipated design. The research study has focused on financial market volatility mispricing and measurement of the financial risk in Indian money market have wide scale repercussion on the economy as a whole. Hence there is a necessity to understand time path and nature of volatility of stock returns. In this study, an attempt has been made to analyze the behavior of volatility in the Bombay Stock Exchange Index shares and other share capital market in India. The nature of volatility persistence, its possible relationship with foreign institutional investment and the flow of unexpected news have been examined in this study.
\end{abstract}

Keywords: Volatility, Financial Risk, Money Market, portfolio and share capital

A Department of Business Management, Indira Gandhi National Tribal University, Amarkantak-MP, India, sri_cbm@yahoo.com 


\section{Introduction}

The present research paper has focused on the measurement of financial risk in money market and mispricing of volatility. The study first focused on the various types of risk aggregation with a diversification effect are applied in financial risk management with reference to the Indian money market. Some global stock market and financial market values also consider under the firm-wide economic capital by aggregating credit, market, operational, and other risk categories with a diversification effect. In distinction, most Indian stock market related share values and Indian banks market values are aggregate credit and market risk categories without the diversification effect. They usually aggregate the risk of money market bond values and equities with the diversification effect in their market portfolio by quantifying a linear correlation between stock prices and interest rates. Further the research study indicates the effect of macroeconomic announcements on the returns, volatility and correlation of Indian money markets as well as explored the Risk in the financial market effects on the EPS. The presently These issues are analyses taking into account the phenomenon of asymmetric volatility of mispricing and incorporating the period of financial turmoil caused by the Indian Financial Crisis. The Research study focuses the attention on the emerging markets of the context of Indian money and capital market. The research paper given details of the ARCH model, introduced by Engle (1982) and later generalized by Bollerslev (1986) spawned many practical studies modeling mispricing of volatility in developed markets in India. Later, there have been rather a few studies focused on emerging stock markets as well. Researchers have increasingly used provisional volatility models such as ARCH, GARCH and their extensions, as these models have facilitated them to model some of the empirical symmetries. Starting with the innovative work of Mandelbrot (1963) and Fama (1965).

\section{Literature Review of the study}

- Viceira (2012) there is a small empirical literature decomposing nominal bond returns into economically interpretable shocks to real interest rates, ination expectations, and risk premia, and estimating the covariances of these components with stock returns.

- Duce and Kan (1996) In this paper we want to model a time-varying covariance between state variables and the stochastic discount factor, which can switch sign and point out that this can be done within an ad new framework if we allow the state variables to be bond yields rather than fundamental macroeconomic variables.

- Bekaert and Harvey (200o) Analyzed equity returns in a group of Emerging markets before and after financial reforms.

- Nilsson (2002) has explored that stock market liberalization can lead to excess volatility possibly on account of noise trading for Nordic stock markets using the Markov regime-switching model.

- Hamao and Mei (2001) examined the impact of foreign and domestic trading on market volatility for Japan and find no systematic evidence that foreign trading tends to increase market volatility.

- Furfine (1999) describes the size, concentration, intra-day timing and analyses bank relationship patterns, particularly with respect to size of institutions.

- Angelini (200o) discusses the implications of timing of overnight transactions in the Italian electronic deposit market during periods of uncertain liquidity. 
- Cassola and Morana (2006) estimate the factors that explain the volatility and its persistence in the overnight segment of the euro money market, which shows repetitive intra-day, daily and monthly patterns that can be explained by market microstructure.

- Black and Scholes (1973) on option pricing assumes that all option prices on the same underlying asset with the same expiration date and different exercise prices should have the same implied volatility.

- Rubinstein (1994) suggest that the volatility smile can occur if the volatility of an underlying stock or market index is expected to be a function of both time and the level of future stock price, although empirical tests.

- Varma (2002) In contrast, limited research on this subject is available for India owing to the nascent nature of its derivatives market. The previous work provides evidence for the existence of a volatility smile in the Indian options market.

- Kannan, and Misra (2006) find that deeply in- and out-of-the money options have higher implied volatility than at-the-money options and that volatility is higher for far month option contracts than for near month option contracts.

- Hull and White (1987) explain an option-pricing problem of a European call on assets having stochastic volatility. Determine the prices of put options non dividend paying stocks in a series form, holding the stochastic volatility independent of the stock price. The study finds the volatility to be correlated with the stock price. The frequent overpricing of options by the Black-Scholes model as well as the degree of overpricing increases with the time to maturity.

- Rubinstein (1994) develops a new method for inferring risk-neutral probabilities (or state-contingent prices) from the simultaneously observed prices of S\&P 500 index options following the crash of 1987. These probabilities are then used to infer a unique, fully specified recombining binomial tree that is consistent with these probabilities, where a simple backwards recursive procedure solves for the entire tree.

- Bakshi, Cao, and Chen (1997) examine the pricing and hedging performance of different option pricing models compared to the Black-Scholes model for S\&P 500 call options from June 1, 1988 through May 31, 1991. Alternative models are examined from three perspectives: (1) internal consistency of implied parameters/volatility with relevant time series data, (2) out-of-sample pricing, and (3) hedging.

- Dumas (1998) develop a Deterministic Volatility Function (DVF) model for option pricing. This model fits different specifications of the volatility using S\&P 500 index options from June 1988 through December 1993. A relatively parsimonious volatility function works well for describing the observed volatility structure, whereas the Black-Scholes constant volatility model appears to be better for determining hedge ratios.

- Steven Thorley (2006) carried out an interesting study on the characteristics of minimum-variance (MV) portfolios and found that MV portfolios, based on the 1,ooo largest U.S. stocks over the period 1968-2005 achieved a volatility reduction of about $25 \%$ while delivering comparable or even higher average returns than the broad market portfolio.

- Blitz and Van Vliet (2007) presented that portfolios of stocks with the lowest historical volatility are associated with Sharpe-ratio improvements that are even greater than those.

- Documented by Clarke et al. (2006), and have a statistically significant positive alpha. They found that low beta stocks had higher returns than predicted while the reverse held for high beta stocks.

- Baker and Haugen (2012) covered stocks of 21developed countries and 12 emerging markets over the time period of 1990 to 2011 and found that low-risk stocks outperform. 
- Pandey and Prachetas (2012) examined the risk anomaly on 51 stocks of NSE for a period of 12years from May 2000 to April 2012. The analysis gave higher average monthly rate of returns for low volatility stocks when compared with high volatility and market portfolios.

- Rohan Rambhia and Mayank Joshipura (2012) studied Risk Anomaly in Indian Equity Market from the period January 2001 to June 2011 and found that the low volatility portfolio strategy gives a higher absolute return over a long period.

- Sanjay Sehgal, Srividya Subramaniam, and Laurence Porteu DE LA (2012) studied Indian -market and disproved the traditional theory (i.e) higher the risk higher the return.

- Vidisha Garg and Sahaj Wadhwa (2014) studied low volatility anomaly in India and found the results supportive of traditional theory and concluded that investors realize high returns only by bearing high risk.

\section{Objective of the study}

1. To explore Risk and volatility miss pricing and the time-varying behavior of the correlation in the Indian Money markets.

2. To study the measure the financial risk in Indian equity market and examine Indian money market for the existence of risk anomaly

3. To investigate volatility mispricing between money and debt markets in Indian context.

4. To study the scope and trading mechanism of capital money in India.

5. To find the relationship between the equity investment pattern and Indian financial market indices.

\section{Hypothesis of the study}

1. There is no normally disturbing between mispricing of Volatility and money Market returns.

2. There is correlation between two variables of mispricing of Volatility and Indian equity and debt market.

3. There is significance between two variables of the measurement of the liquidity risk and mispricing of Volatility.

\section{Significance of the study}

To control whether the factors related to financing risk management model and Stock Market mispricing of Volatility coin-incidence have an effect on the behavior of the individual investor In the Perspective of the Indian money market. 


\section{Scope of the study}

In this research paper the study has covered the study of co-movement of stock market volatility and the systematic and unsystematic risk system in the Indian stock market, money market and debt market. The time frame is from 2010 to 2016.

\section{Methodology of the study}

This part deals with how the research was designed and the methodology used to determine the factors influencing the individual investment decisions, Exploring the financial risk and Volatility index in the Indian money Market under NSE \&BSE. The survey research design was adopted with a population of approximately 1 million investors from whom a sample of 356 investors was randomly selected for study. Primary data was collected using online Opinion data which were examined by the researcher personally and collected data was coded and tabulated for analysis:

1. Research design: The present research paper has discussed the research design was used for this study. Mugenda and Mugenda (1999) notes that a survey research attempts to collect data from members of a population and describes existing phenomena by asking individuals about their opinion, attitudes, behavior or values of the investors and consider other influence factor.

2. Target population: The target population of this study was all the investors drawn from NSE and BSE which are approximately 1 million Investors in all five regions share capital market in India. In this research paper the study has consider from the five region capital market investors opinions

3. Sampling design and sample size: The study has adopted a simple random sample of five stock market and share capital was selected from which 245 individual investors from it were randomly selected targeting one questionnaire each and secondary data of five years record of NIFTY, NSE and BSE. Random numbers can be obtained using a calculator, a spreadsheet, printed tables of random numbers, or by the more traditional methods of drawing slips of paper from a hat, tossing coins or rolling dice (Neville, Sidney, 2004).

4. Secondary data and primary data sample: The study uses a sample of different market indicators of Nifty 100 stocks. These indicators include Data analysis and primary data also used for this research paper through the semi structure question and majority of information has been drawn from the secondary data:

a) Monthly, quarterly and annual total returns of the index and securities,

b) Monthly, quarterly and annual transaction volume of the index and securities,

c) Monthly, quarterly and annual high and low values of the index,

d) Monthly, quarterly and annual closing prices of Nifty 50 index options.

Along with this the daily, Monthly, Quarterly and annually risk-free rate of return of the Indian stock market and Capital markets index is also used. The data set has been taken for a period 2010-2016. Further, the study used the cross sectional and time-series data.

5. Collection of secondary data: The data on Nifty 100 stocks is procured from Prowess database of Centre for Monitoring Indian Economy (CMIE). The dataset of Nifty 100 options, Ministry of Finance, Ministry of Economics, Department of Statistics and Treasury-bill index is obtained from the official NSE website. 


\section{Data analysis and interpretation}

According to above table the study has displayed the sample size contains five share markets in India, which will be analysed according share values wise and pair-wise. The data has been extracted from the Indian stock market and Mumbai stock market and encompasses the period 2010 to 2016 (1200 observations through online). For this Research study to take into account the Indian Financial crisis, and some selected variable has used the next following model development purpose. Many financial analysts have fixed the beginning of the Indian Financial crisis and banks of our countries responded to the collapse of the economy with unprecedented fiscal stimulus, monetary policy expansion, and institutional bailouts. The data used for this study through secondary and primary to partially overcome the potential problem of non synchronous data, which may arise because there are instants in which markets are closed in one Region and open in another. The returns are computed as log differences using day to day, weekly and monthly, the index prices to avoid any potential day of the week biases.

\section{Correlation structure between financial risk factors and mispricing of volatility in Indian financial market}

The research study has adopted the correlation structure between financial risk factors and mispricing of volatility by using a copula. A copula represents a joint distribution as a function of the marginal distributions. Using a copula $C\left(U_{1} \ldots . U_{d}\right)$ the joint cumulative probability (distribution function) of the $\mathrm{d}$ random variables is represented as

$\operatorname{Pr}\left(\mathrm{X}_{1}<\mathrm{x}_{1} \ldots \ldots \mathrm{X}_{\mathrm{d}}<\mathrm{x}_{\mathrm{d}}\right)=\mathrm{C}\left(\operatorname{Pr}\left(\mathrm{X}_{1}<\mathrm{x}_{1}\right) \ldots . \operatorname{Pr}\left(\mathrm{X}_{\mathrm{d}}<\mathrm{X}_{\mathrm{d}}\right) \ldots \ldots \ldots(1)\right.$

The research study to adopted the maximum likelihood method, the copula density c $\left(\mathrm{U}_{1} \ldots .\right.$. $\left.U_{d}\right)$ for the couple $C\left(U_{1} \ldots . . U_{d}\right)$ is given equation statement

$$
C(u 1 \ldots \ldots . . u d)=\frac{\partial c(u 1 \ldots u d)}{\partial u 1 \ldots . . . \partial u d} \ldots \ldots . .(2)
$$

From above equation there are two approaches to estimate a copula from a selected sample on is risk factor in financial market and mispricing of volatility sample $\left(\mathrm{u}_{11} \ldots \mathrm{u}_{21}\right) \ldots \ldots\left(\mathrm{u}_{1 \mathrm{~N}} \ldots\right.$ $\mathrm{u}_{2 \mathrm{~N}}$ ). The according to the non-parametric approach based on joint empirical distribution. The next one is a parametric approach to assume a parametric copula and estimate the parameters to determine the risk factor of the money market and equity market values.

A nonparametric copula $C_{N P}\left(u_{1}, u_{2}\right)$ is made from a combined empirical distribution function of the selected sample from the listed under of the Money market and equity market $\left(\mathrm{u}_{11}\right.$, $\left.\mathrm{u}_{12}\right) \ldots\left(\mathrm{u}_{1 \mathrm{~N}}, \mathrm{U}_{2 \mathrm{~N}}\right)$

$\lambda_{L}=\lim _{u \rightarrow \infty} \operatorname{pr}(U 2<u)=\lim _{n \rightarrow \infty} \frac{(U, u)}{u} \square \ldots \ldots \ldots . .(3)$

The upper-tail dependence variable is indicated $\chi U$ is defined as 
$\lambda_{u}=\lim _{u \rightarrow \infty} \operatorname{pr}(U 2<u) U 1<u=\lim _{n \rightarrow \infty} \frac{1-2 u+C(U, u)}{1-u} \square$

$\chi_{\mathrm{L}}$ and $\chi_{\mathrm{u} \text { represent }}$ the strengthen the low and upper tail tendency to correlated the risk factor and mispricing of volatility.

\section{Parametric copulas for the test of financial risk in Indian Market}

The research study used the Six parametric copulas are utilized in the following variables to evaluated the. Three of them are Archimedean copulas, which include the Gumbel, Clayton, and Frank copulas. The other three are implied copulas, which include the Gaussian, t, test and mixed-Gaussian copula.

Table 1. Bivariate Archimedean copulas and their tail dependence to test the risk and mispricing volatility

\begin{tabular}{|c|c|c|c|c|}
\hline \multirow{2}{*}{ Copula } & \multirow{2}{*}{ Parameter } & \multirow{2}{*}{ Expression } & \multicolumn{2}{|c|}{ Tail dependence } \\
\cline { 3 - 5 } & $\gamma$ & $\operatorname{Exp}\left\{-\left(\left(-1 n \mathrm{nu}_{2}\right)^{\gamma}+\left(-1 n \mathrm{nu}_{2}\right)^{\gamma / 1 / \gamma}\right\}\right.$ & $2-2^{1 / \gamma}$ & 0 \\
\hline Gumbel & $\alpha$ & $\left(\mathrm{u}_{1}^{-\alpha}+\mathrm{u}_{2}^{-\alpha}-1\right)-^{1 / \alpha}$ & 0 & $-2^{1 / \alpha}$ \\
\hline Clayton & $\sigma$ & $-1 / \sigma i n 1+1+\frac{(e-1)(e-2)}{e-1}$ & 0 & 0 \\
\hline Frank & $\sigma$ & & \\
\hline
\end{tabular}

The study has used Gumbel and Clayton copulas equation are defined for positively correlated data. The research paper can be applied for negatively correlated data by rotating one axis around the other factors in the research paper.

\section{Measuring the financial risk and mispricing volatility diversification effect on the financial market in India}

The present research study has consider the profitable portfolio that contain more than 5 oo billion Rupees for the duration of last six years from 2010 to 2016. This is the represent average portfolio of Indian money market. The study adopt the 99\% VaR and 95\% ES estimated for the financial risk measurement and misprice of the stock market.

In this research paper calculate the $99 \% \mathrm{VaR}$ and $95 \% \mathrm{ES}$ with the help of following equation, the research study has assumed AFR and AMPV be the amount of financial risk and amount of mispricing volatility in the current Indian money market and equity market respectively. The changes of the above two major variable in the study $S_{t}-\operatorname{In} S_{t}+S$ and the rate of interest is for the 6 years, the changes of the interest rate is $\mathrm{rt}-\mathrm{rt}+\mathrm{r}$. the research paper calculate the changes of the money market portfolio values according to the following equation

$$
\begin{aligned}
& \Delta \mathrm{PV}=\mathrm{AS} \mathrm{S}_{\mathrm{t}}{ }^{\mathrm{e}} \Delta^{\mathrm{s}} / \mathrm{s}_{\mathrm{t}}+\mathrm{e}^{-(\mathrm{rt}+\mathrm{r}) \mathrm{T}} / \mathrm{e}^{-\mathrm{rt}} . \\
& =\mathrm{AS} \Delta \mathrm{S}-\mathrm{AB}(\Delta \mathrm{r})^{\mathrm{T}}
\end{aligned}
$$


From the above information the study research paper has obtained by the converting the quantile function for each marginal distribution from simulated by the information using the specific couple.

The simple sum of the variable values of $95 \%$ of ES for each financial risk factor is given by the applying for the lower rate of the average values of the each portfolio is $65 \% \mathrm{~S}_{7.5}$ and Upper variable average values represent by the $r_{95 \%}$. This values express by the following equation

Sum of ES $=\operatorname{AS}\left(\Delta \mathrm{S}_{7.5 \%}\right)+\mathrm{AB}\left(\Delta \mathrm{r}_{95 \%}\right)^{\mathrm{T}} \ldots \ldots \ldots . .(7)$

Table 2. VaR and ES for the Measurement of the Financial Risk and mispricing of the volatility their simple sum

\begin{tabular}{|c|c|c|c|}
\hline \multicolumn{2}{|c|}{ VaR (99\%) } & \multicolumn{2}{c|}{ ES (95\%) } \\
\hline Financial Risk & Mispricing & Financial Risk & 2.34 \\
\hline 6.52 & 3.41 & 8.58 & \multicolumn{2}{c|}{ Sum of ES } \\
\hline \multicolumn{2}{|c|}{ Sum of VaR } & \multicolumn{2}{c|}{10.92} \\
\hline \multicolumn{2}{|c|}{9.93} & \\
\hline
\end{tabular}

The present above table announced the result about the financial risk factor and mispricing of the volatility, it has measure a diversification effect by the reduction rate of the aggregated $\mathrm{VaR}$ and ES from the simple sum of VaR and ES. VaR and ES for each copula and diversification effect of the systematic risk and unsystematic risk of the financial market in India

The result summarizes VaR and ES for the selected portfolio under listed share of the company. The selected portfolio sample joint distribution for risk factors is made by each estimated copula with the marginal distributions in table. For the nonparametric copula, the pseudo sample is converted to a set of risk factors by taking quantiles for the marginal skew-t distributions. For each parametric copula, the study has selected 356 sample of portfolio from out of the 100,000 portfolio from last six years on random basis, the bivariate vectors and calculate $\mathrm{VaR}$ and ES with the marginal skew-t distributions. Iterating the procedure 50 times, the table obtain the average and standard deviation of VaR and ES.

Table 3. VaR and ES using copula estimated from Indian market data from 2010 to 2016

\begin{tabular}{|l|c|c|c|c|c|c|}
\hline Copula & VaR 99\% & Std dev. & $\begin{array}{c}\text { Diversification } \\
\text { effect }\end{array}$ & ES95\% & Std dev. & $\begin{array}{c}\text { Diversification } \\
\text { effect }\end{array}$ \\
\hline Nonparametric & 2.42 & - & $35 \%$ & 1.25 & - & $15 \%$ \\
\hline Gumbel & 2.69 & 0.05 & $36 \%$ & 1.69 & 0.05 & $19 \%$ \\
\hline Rotated-Gumbel & 2.85 & 0.05 & $35 \%$ & 2.85 & 0.90 & $25 \%$ \\
\hline Clayton & 3.56 & 0.06 & $34 \%$ & 4.68 & 0.08 & $17 \%$ \\
\hline Rotated-Clayton & 4.58 & 0.02 & $39 \%$ & 4.53 & 0.04 & $28 \%$ \\
\hline Frank & 1.26 & 0.02 & $41 \%$ & 4.69 & 0.04 & $29 \%$ \\
\hline Gaussian & 0.96 & 0.03 & $42 \%$ & 4.26 & 0.06 & $45 \%$ \\
\hline t-test & 2.38 & 0.04 & $48 \%$ & 5.69 & 0.08 & $16 \%$ \\
\hline Mixed-Gaussian & 5.68 & 0.02 & $12 \%$ & 8.56 & 0.08 & 9 \\
\hline
\end{tabular}

The results discussion of the above table is diversification effect (1-48\%) is smaller than that of VCV (35\%) in table, which approves that the Gaussian assumption of VCV for margins causes underestimation of $\mathrm{VaR}$ and ES. The diversification effect of the nonparametric copula near- 


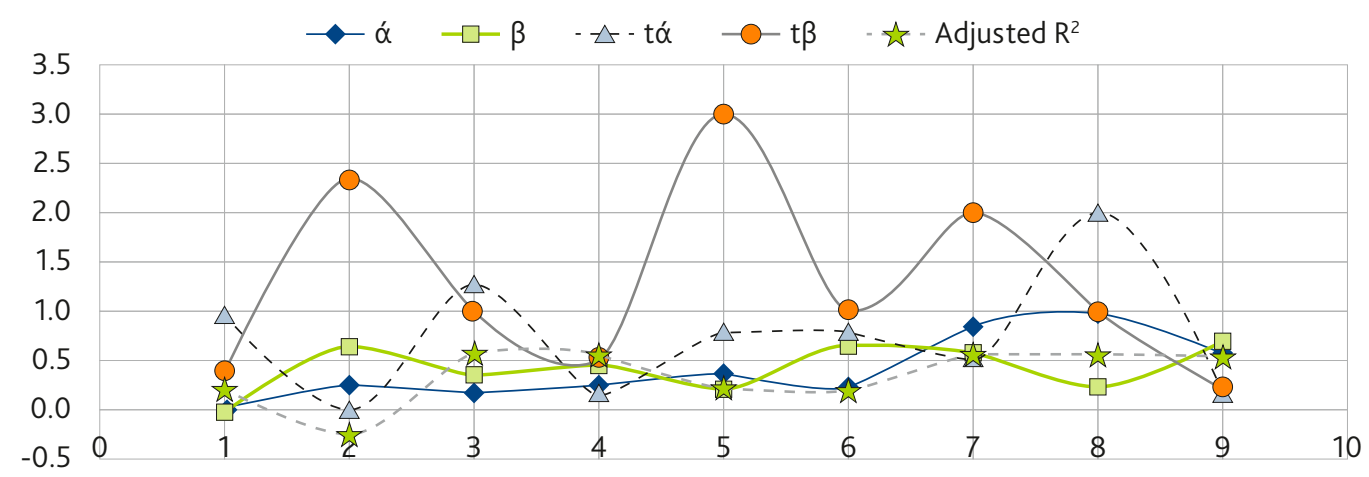

Chart 1. VaR and ES using copula estimated from Indian market data from 2010 to 2016

ly equals that of the HS method. Finally the research study has drawn the conclusion the diversification effect for mixed-Gaussian copula (VaR: 12\%, ES: $9 \%$ ) selected by BIC is the smallest, and is much smaller than that for the other copulas. Unlike the other parametric copulas, a mixed-Gaussian copula can capture both positive and negative linear correlations so that it fits to the selected portfolio in the Indian financial market with related to risk factor and mispricing of the share values better than the other parametric copulas.

\section{Mean and Volatility from GARCH to determine the systematic and unsystematic risk value}

The coefficient of the mean equation and volatility equation are adopted the evaluated financial systematic risk and unsystematic risk measurement, The significance of the coefficients of volatility of mispricing is one per cent level indicates the presence of strong GARCH effect in the call market volatility. Consequently, the rest of this research study uses the daily volatility estimated by the abovementioned GARCH equation.

Table 4. Mean and Volatility from GARCH

\begin{tabular}{|c|c|c|}
\hline & Co-efficient & P-value \\
\hline C & 0.12 & 0.00 \\
\hline WT_AVG(-1 & 0.69 & 0.00 \\
\hline C & 0.03 & 0.00 \\
\hline RESID(-1)^2 & 0.63 & 0.05 \\
\hline GARCH(-1) & 0.50 & 0.10 \\
\hline R-squared & 0.61 & \\
\hline D-W Stat & 3.90 & \\
\hline
\end{tabular}

Applied the CAPM Regression to determine the money market factor with related to risk and mispricing of volatility:

$\mathrm{CAPM}=\left(_{\mathrm{t}}-\right)=\alpha+\beta\left(\boldsymbol{r}_{m t}-\boldsymbol{r}_{f t}\right)+\boldsymbol{e}_{\mathrm{t}}$ 
Table 5. CAPM model excess returns on volatility of mispricing in selected portfolios are regressed on the money market factor

\begin{tabular}{|c|c|c|c|c|c|}
\hline Portfolios & $\alpha$ & $\beta$ & $\mathrm{t}_{\alpha}$ & $\mathrm{t}_{\beta}$ & ${\text { Adjusted } \mathrm{R}^{2}}^{\mathbf{\alpha}}$ \\
\hline 1 & 0.01530 & 0.00236 & 0.98695 & 0.36592 & 0.23522 \\
\hline 2 & 0.25698 & 0.65032 & 0.02365 & 2.36585 & -0.2356 \\
\hline 3 & 0.20365 & 0.36924 & 1.25698 & 1.02365 & 0.56980 \\
\hline 4 & 0.25698 & 0.46980 & 0.23687 & 0.57895 & 0.56895 \\
\hline 5 & 0.36548 & 0.25646 & 0.78543 & 3.02658 & 0.23587 \\
\hline 6 & 0.25736 & 0.66823 & 0.80135 & 1.02365 & 0.25689 \\
\hline 7 & 0.86545 & 0.56982 & 0.56890 & 2.03690 & 0.54896 \\
\hline 8 & 0.98652 & 0.25660 & 2.03652 & 1.03256 & 0.56874 \\
\hline 9 & 0.60542 & 0.69856 & 0.20368 & 0.23658 & 0.56981 \\
\hline 10 & 0.10325 & 0.56923 & 0.56800 & 0.85686 & 0.56897 \\
\hline
\end{tabular}

The CAPM regression results are consistent with high risk impact factor on the selected portfolio and the research study has observed the value of $\beta$ is cumulative in a continuous manner from portfolio 1 (Low volatility portfolio) to portfolio 10 (High volatility portfolio), thus the portfolio 1 has the lowest systematic risk and portfolio 8 has the highest systematic risk.

The selected portfolio from 1 to 10 has lowest total volatility as well as lowest systematic volatility among given portfolios and portfolio 8 has highest total volatility as well as highest systematic volatility among given portfolios. Thus high volatility portfolio yields high return and low volatility portfolio yields low returns. The significant alpha values imply that CAPM is not a good indicator of returns of the selected portfolio. Specific other factors which are affecting the returns on volatility of mispricing and risk in financial market portfolios.

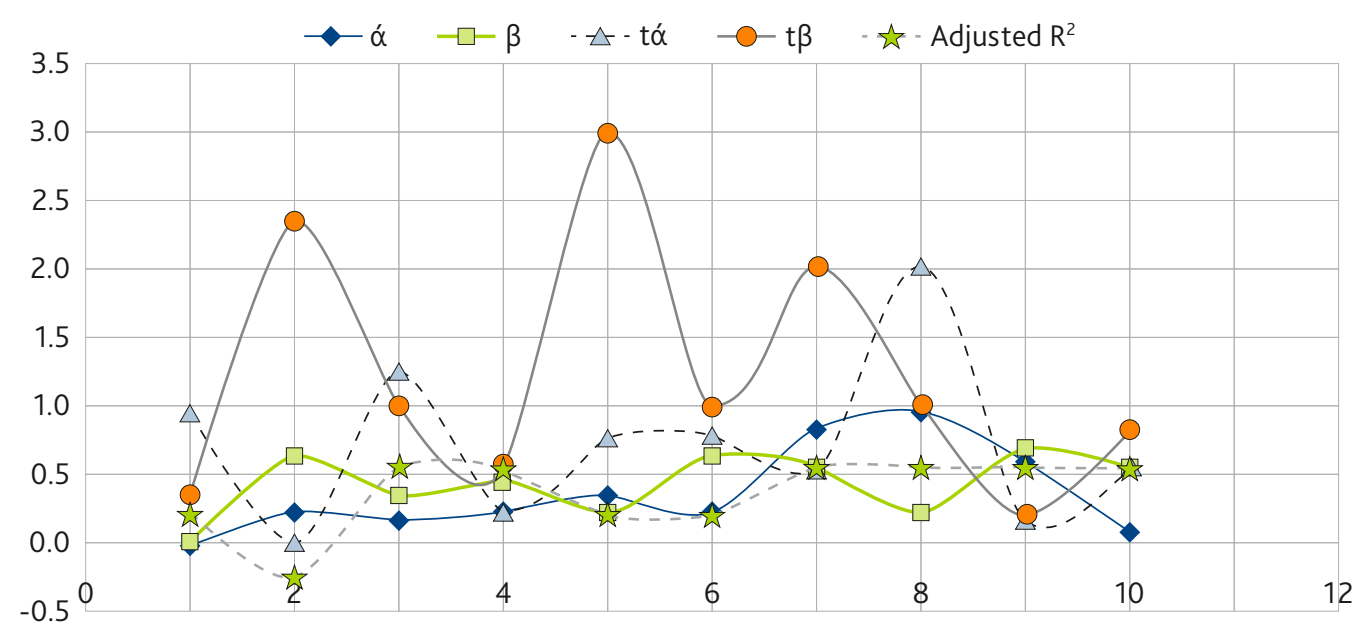

Chart 2. CAPM model excess returns on volatility of mispricing in selected portfolios are regressed on the money market factor 


\section{Symmetric Conditional Volatility Model to determine the risk and mispricing values: GARCH}

The result of GARCH and cross correlation the return series of the index shows ARCH effect in all the periods studied from 2010 to 2016. The most standard of the ARCH models, to model volatility of mispricing in financial market of Nifty returns in NSE \&BSE. The research study analysis with help of the R-software uses maximum likelihood process to estimate the model under the assumption that the errors are conditionally normally distributed. The coefficient values to calculate the residual of mean equation and then computes an exponential smoothing estimator of the initial values with smoothing parameter, $\lambda=0.5$. The research study have used the defaulting initialization process in this work throughout. The results from the model estimated for different periods are reported in the above table. The sum of ARCH and GARCH coefficients estimated by the model is near to 0.9 in both the sub-periods as well for the entire data set. From the 2010-2012 during period, the volatility in Indian financial markets was spinier (higher $\alpha$ ) and less determined (lower $\beta$ ) than the 2012-2014 period and the entire data set. The sum of coefficients being significantly less than one indicates that volatility is mean reverting. The z-statistics as stated in the table is valid only if errors are conditionally normally distributed. The standard errors calculated under the assumption of conditionally normally distributed error terms, are not consistent if the errors are not normally distributed.

Table 6. Results from GARCH model

\begin{tabular}{|c|c|c|c|}
\hline & 2010 to 2012 & 2012 to 2014 & 2014 to 2016 \\
\hline Constant & $\begin{array}{l}-5.0235 \\
(0.5698)\end{array}$ & $\begin{array}{c}0.8652 \\
(0.0210)\end{array}$ & $\begin{array}{l}-1.2530 \\
(0.0543)\end{array}$ \\
\hline$\omega$ & $\begin{array}{c}3.5680 \\
(1.5680)\end{array}$ & $\begin{array}{c}2.0356 \\
(-0.2130)\end{array}$ & $\begin{array}{c}0.5680 \\
(0.2560)\end{array}$ \\
\hline$\alpha$ & $\begin{array}{c}0.2153 \\
(0.4503)\end{array}$ & $\begin{array}{c}-0.5680 \\
(0.5620)\end{array}$ & $\begin{array}{c}5.0235 \\
(1.0235)\end{array}$ \\
\hline$\beta$ & $\begin{array}{c}1.0235 \\
(0.2350)\end{array}$ & $\begin{array}{c}0.2568 \\
(0.7820)\end{array}$ & $\begin{array}{c}1.0235 \\
(0.5489)\end{array}$ \\
\hline Annualized long-run Volatility implied by $\omega, \alpha \& \beta$ & 21.0256 & 16.2460 & 9.2568 \\
\hline \multicolumn{4}{|c|}{ Standardized Residuals: Descriptive Statistics } \\
\hline Mean & 5.7845 & -2.1254 & 0.9583 \\
\hline Std. Dev. & 0.9051 & 0.5648 & 0.0564 \\
\hline Skewness & 0.0478 & 0.0875 & 0.5680 \\
\hline Kurtosis & 3.2560 & 2.5789 & 6.8012 \\
\hline Jarque-Bera & 61.2560 & 38.2570 & 19.5681 \\
\hline Probability & 0.0000 & 0.0010 & 0.0250 \\
\hline
\end{tabular}

Parenthesis are z-statistics associated with coefficients * Significant at $5 \%$ level. ** Significant at $1 \%$ level. 
Table 7. Cross-correlation of Squared Residuals from GARCH Models with the Lagged Residuals

\begin{tabular}{|c|c|c|c|}
\hline & $\mathbf{2 0 1 0}$ to 2012 & $\mathbf{2 0 1 2}$ to 2014 & $\mathbf{2 0 1 4}$ to 2016 \\
\hline Lag=1 & -0.0452 & -0.5680 & -0.5012 \\
\hline Lag=2 & -1.0235 & -0.2560 & 0.9856 \\
\hline Lag=3 & 0.5680 & 0.4216 & -0.5681 \\
\hline Lag=4 & 1.0235 & -2.0325 & 0.5680 \\
\hline Lag=5 & 0.1521 & 0.3625 & -0.1524 \\
\hline
\end{tabular}

\section{Regression Formula:}

Regression Equation $(\mathrm{y})=\mathrm{a}+\mathrm{bx}$ Slope $(\mathrm{b})=(\mathrm{N} \Sigma \mathrm{XY}-(\Sigma \mathrm{X})(\Sigma \mathrm{Y})) /\left(\mathrm{N} \Sigma \mathrm{X}^{2}-(\Sigma \mathrm{X})^{2}\right)$ Intercept $(\mathrm{a})$ $=(\Sigma \mathrm{Y}-\mathrm{b}(\Sigma \mathrm{X})) / \mathrm{N}$

The test for the study have selected share of particular market in the series is a test of the null hypothesis that $H$ o. If the hypothesis cannot be rejected the series is assumed to be non-stationary.

Table 8. The Augmented Dickey-Fuller test

\begin{tabular}{|c|c|c|}
\hline \multirow{2}{*}{ Share Market Region } & \multicolumn{2}{|c|}{ Augmented Dickey-Fuller test } \\
\cline { 2 - 3 } & Price series & Return series \\
\hline 2010 & $3.54585265(0.542323)$ & $-8.231546874(0.00125)$ \\
\hline 2011 & $-11.215365012(0.540231)$ & $5.021354210(0.054864)$ \\
\hline 2012 & $2.958590609(0.859675)$ & $-4.958575(0.0405849)$ \\
\hline 2013 & $1.048574984(0.00575905)$ & $6.49585764(0.0398485)$ \\
\hline 2014 & $5.069685474(0.0485738)$ & $7.045958424(0.04958420)$ \\
\hline 2015 & $0.05689374(0.00154605)$ & $2.23568925(0.03568905)$ \\
\hline 2016 & $2.0568422584(0.00575905)$ & $36.56892454(0.0 .587665)$ \\
\hline
\end{tabular}

Note: $p$-values displayed as (.). Critical value at $5 \%$ significance level

The present research study has announced the result from the above table distributional properties of the return series generally appear to be non-normal. All the return series have negative skewness and are leptokurtic (the Kurtosis coefficient exceeds three). The Jarque-Bera test rejects Normality of the returns. These characteristics have been well recognized by a number of other studies in the financial literature.

Table 9. Summary of the descriptive statistics

\begin{tabular}{|l|c|c|c|c|c|}
\hline \multicolumn{1}{|c|}{ Time period } & Mean & $\begin{array}{l}\text { Standard } \\
\text { deviation }\end{array}$ & Skewness & Kurtosis & Normality \\
\hline January 2010 to March 2016 & 0.0584510 & 0.254684 & -0.256546 & 3.25256 & $\begin{array}{c}35.12382 \\
(0.25516)\end{array}$ \\
\hline January 2010 to March 2016 & 0.5896478 & 0.554830 & 0.589752 & 4.5625 & $\begin{array}{r}15.58876 \\
(1.56356)\end{array}$ \\
\hline January 2010 to March 2016 & 0.256893 & 0.256432 & 0.652345 & 1.25632 & $\begin{array}{l}6.085365 \\
(0.58634)\end{array}$ \\
\hline January 2010 to March 2016 & 0.1254862 & 0.157831 & -3.025401 & 3.2562 & $\begin{array}{l}5.235620 \\
(0.25789\end{array}$ \\
\hline January 2010 to March 2016 & 0.001250 & 0.589600 & -0.652310 & -0.5624 & $\begin{array}{l}21.158465 \\
(0.21548)\end{array}$ \\
\hline
\end{tabular}


Table shows the unconditional correlation matrix. Focusing the attention on the correlation between the one market and all other rest of four markets it is observed that the highest correlations are those with Mumbai, Hyderabad and Chennai (around o.6). This result makes sense due to their condition of mature market and tigers, respectively. The correlation with Mumbai and Chennai, the other two tigers, is around 0.45 and the correlation with the cubs is around 0.4. Therefore, as it was expected, correlation. With the Mumbai market increases with the other four market level of development. Finally, it is remarkable the low correlation between Bangalore and Delhi share market.

Table 10. GJR GARCH estimates Model: The GARCH effect and leverage impact on dependent series (includes log values of daily Nifty 100 returns and closing option prices in the Indian market and determine the financial risk and mispricing Volatility in the Stock Market)

\begin{tabular}{|c|c|c|c|c|c|c|c|c|}
\hline Parameters & $\begin{array}{c}\text { Daily Nifty } \\
50 \text { returns }\end{array}$ & $\begin{array}{c}\text { Average } \\
\text { Monthly } \\
\text { Nifty 50 } \\
\text { Returns }\end{array}$ & $\begin{array}{c}\text { Average } \\
\text { Quarterly } \\
\text { Nifty 50 } \\
\text { Returns }\end{array}$ & $\begin{array}{c}\text { Average } \\
\text { Annually } \\
\text { Nifty 50 } \\
\text { Returns }\end{array}$ & $\begin{array}{c}\text { Out of the } \\
\text { money put } \\
\text { options }\end{array}$ & $\begin{array}{c}\text { In-the- } \\
\text { money put } \\
\text { options }\end{array}$ & $\begin{array}{c}\text { Out-of-the } \\
\text { money call } \\
\text { options }\end{array}$ & $\begin{array}{c}\text { In-the- } \\
\text { money call } \\
\text { options }\end{array}$ \\
\hline$\omega$ & $0.0520^{* *}$ & $2.0360^{*}$ & 2.35560 & 3.2210 & 0.2360 & 0.2100 & 0.00 & -0.012 \\
\hline$\beta$ & 0.286530 & 1.0235 & $1.85560^{* * *}$ & 1.2350 & 0.2130 & 0.002 & $0.00^{*}$ & $0.965^{* *}$ \\
\hline$\alpha$ & $0.5600^{* * *}$ & 2.12533 & $5.2315^{* *}$ & $0.9568 * *$ & 0.0210 & $0.100^{* *}$ & 0.142 & 0.451 \\
\hline$\gamma$ & 0.1254 & $1.0456^{* *}$ & 4.32665 & .96325 & 0.200 & 0.001 & 0.001 & 0.686 \\
\hline
\end{tabular}

* Significant at the 10\% level, ** Significant at the 5\% level and *** Significant at the $1 \%$ level

Table 11. Impact of pessimism in the money put and call option in the derivative market on objective financial risk premium in the Indian stock market with following of five regions

\begin{tabular}{|c|c|c|c|}
\hline Parameters & Unstandardized coeff. & t-statistic & Sig. \\
\hline (Constant) & 0.2310 & 3.02154 & 0.0546 \\
\hline $\mathrm{RP}_{-1}$ & 0.5420 & -0.2654 & 0.0054 \\
\hline $\mathrm{RP}_{-2}$ & 0.1002 & 5.02350 & 0.2001 \\
\hline Pessimism & 0.00231 & 37.0215 & 0.0048 \\
\hline \multicolumn{2}{|c|}{ Adjusted R square } & & 0.47235 \\
\hline
\end{tabular}

The above Table explored the values of the GJR GARCH estimates of Nifty 50 returns of the Indian capital for the period of Five Years, in and out of the money put and call options. It is seen that the leverage effect (measured by the interaction dummy variable "It-1" in equation of the GARCH Model) in the order for all the variables and is verified by a positive $\gamma$ parameter, except in out-of-the money call option where it is Positive but insignificant. The parameter $\gamma$ is Negative and significant for in-the-money put option and in-the-money call options. It is insignificant for the Nifty 50 return series and the out-of-the money put option series although the sign is Negative. The GJR GARCH estimates are used to generate the objective density (p) and risk neutral density (q) for calculating empirical pricing estimation and determined the financial risk for the evaluating the EPS. The above tables Strongly Indicating that the probability distribution of objective and risk neutral density functions in the share market of India in the above selected five regions. 


\section{Conclusion}

The research paper has drawn the conclusion the Using of data from 2010 to 2016 the research paper attempt to study mispricing of low volatility anomaly in Indian market. The returns, risk and volatility are measured average value of the selected portfolio under listed companies in this present research study, the financial risk of a stock or volatility is defined as the standard deviation of average returns over a period of from last six years. This period of six years is called the estimation period. Then stocks are sorted into quintiles on the basis of trailing volatility. The research paper found the rebalance portfolios every month, Years and hold them for one years as well year. Monthly returns on these volatility sorted quintiles are observed.

This research paper concluded is based on dynamic relationship between money markets movement, Financial Risk of Equity Market and mispricing of volatility of stock market. The present Research Paper has started from absolute value of data for checking the normality which was converted to log. Statistics was yielded the application of Descriptive Statistics test, GJR GARCH estimates Model, Augmented Dickey-Fuller test, Regression analysis, cross sectional analysis and results have shown that stationary is at level form in both data series. Then, the Research paper observed the coefficient of correlation between these variables and taken the results that there is negative correlation.

\section{References}

1. Aminsky, G.L., Schmukler, S.L. 2001. On Booms and Crashes: Financial Liberalization and Stock Market Cycles.

2. Agrawal, G.D. 1992. Mutual Funds and Investors' Interest. Chartered Secretary 22/1, 23.

3. Atmaramani, K.A. 1984. Issue of Non-Convertible Debentures by public limited companies. Chartered Secretary 14/7, 463-468.

4. Adler, M., Dumas, B. 1984. Exposure to currency risk: Definition and measurement. Financial Management 13, 41-50.

5. Albuquerque, R., Vega, C. 2009. Economic news and international stock market co-movements. Review of Finance 13(3), 401-465.

6. Amihud, Y. 1994. Exchange rates and the valuation of equity shares. Exchange Rates and Corporate Performance, 49-59. Eds. Y. Amihud and R. Levich.

7. Andersen, T.G., Bollerslev, T., Diebold, F.X., Vega, C. 2003. Real-time price discovery in global, stock, bond, and foreign exchange markets. Journal of International Economics 73 (2), 251-277.

8. Andersen, T.G., Bollerslev, T., Diebold, F.X., Vega, C. 2007. Micro effects of macro announcements: Real-time price discovery in foreign exchange. American Economic Review 93 (1). 38-62.

9. Aggarwal, R., Inclan, C., Leal R. 1999. Volatility in Emerging Stock Markets. Journal of Financial and Quantitative Analysis 34(1), 33-55.

10. Akgiray, V. 1989. Conditional Heteroskedasticity in Time Series of Stock Returns: Evidence and Forecasts. Journal of Business 62, 55-80.

11. Alexander, C. 1998. Volatility and Correlation: Measurement, Models and Applications", Risk Management and Analysis, Vol.I: Measuring and Modeling Financial Risk, Ed C.Alexander, John Wiley and Sons, New York, 125-171.

12. Andersen, T.G., Bollerslev, T. 1998. Answering the Skeptics: Yes, Standard Volatility Models Do Provide Accurate Forecasts. International Economic Review 39, 885-905. 
13. Andersen, T.G., Bollerslev, T., Diebold, F.X., Labys, P. 1999. Microstructure Bias and Volatility Signatures. Unpublished Manuscript, New York University.

14. Balasubramaniam, N. 1993. Corporate Financial Policies and Shareholders Returns : The Indian Experience, Himalaya Publishing, Bombay, 266.

15. Barua, S. K., Raghunathan, V. 1982. Inflation Hedge in India - Stocks or Bullion Working Paper No. 429, (July- Sept), Indian Institute of Management, Ahmedabad.

16. Barua, S. K., Madhavan, T., Raghunathan, V. 1987. Implications of Changes in the Holding, period and Other, parameters on Systematic Risk and Performance of a Security. Working Paper No. 664, (Jan-Mar), Indian Institute of Management, Ahmedabad.

17. Barua, S. K., Madhavan, T., Varma, J. R. 1991. Indian Convertible Bonds with Unspecified Terms: An Empirical Study. Working Paper No. 990, (Oct-Dec), Indian Institute of Management, Ahmedabad.

18. Deardorff, A. V. 1979. One Way Arbitrage and its Implications for the Foreign Exchange Markets. Journal of Political Economy 87, 351-364.

19. European Commission 2007. European Financial Integration Report 2007, EC, Brussels.

20. Fabozzi, F.J., Modigliani F. 2007. Capital Markets: Institutions and Instruments. Prentice-Hall International.

21. Financial Stability Forum 2008. Report on Enhancing Market and Institutional Resilience, FSF, Basel.

22. Howells, P., Bain, K. 2008. Financial Markets and Institutions. Financial Times, Prentice Hall.

23. Prosad, J.M., Kapoor, S., Sengupta, J. 2012. An Examination of Herd Behavior: An Empirical Evidence from Indian Equity Market. International Journal of Trade, Economics and Finance 3/2, 154-157.

24. Prosad, J.M., Kapoor, S., Sengupta, J. 2013. Impact of Overconfidence and the Disposition Effect on Trading Volume; An Empirical Investigation of Indian Equity Market. International Journal of Research in Management and Technology 3/4, 109- 116.

25. Prosad, J.M., Kapoor, S., Sengupta, J. 2014. Theory of Behavioral Finance, accepted for publication in Behavioral Finance and Investment Strategies: Decision Making in the Financial Industry, IGI Global Publications, Hershey, U.S.A.

26. Litterman, R., Scheinkman, J. 1991. Common Factors Affecting Bond Returns. Journal of Fixed Income 1, 54-61.

27. Madura J. 2008. Financial Markets and Institutions. Prentice-Hall International.

28. Mishkin, F.S., Eakins, S.G. 2006. Financial Markets and Institutions. Addison-Wesley.

29. NYSE Group Shares Outstanding and Market Capitalization of Companies Listed, 2009. June 7, 2009. http://www.nyxdata.com/nysedata/default.aspx?tabid=115

30. Nelson, C., Schaefer, S. M. 1983. The Dynamics of the Term Structure and Alternative Immunization Strategies, in Bierwag, G. O. et al. ed., Innovations in Bond Portfolio Management: Duration Analysis and Immunization, Greenwich, CT, JAI Press.

31. Seifert, W.G., Schleitner, A.K., Mattern, F., Streit, C.C., Voth, H.J. 20oo. European Capital Markets, Macmillan, 8.

32. Valdez, S. 2006. Introduction to Global Financial Markets, Palgrave Macmillan.

33. Shiller, R. J. 1990. Market Volatility and Investor Behaviour. American Economic Review 8o(2), 58-62.

34. Varma, J. R. 1996. Bond Valuation and the Pricing of Interest rate Options in India. ICFAI Journal of Applied Finance 2(2), 161-176. 